\title{
Sperm chromatin structure assay results after swim-up are related only to embryo quality but not to fertilization and pregnancy rates following IVF
}

\author{
Zhi-Hong Niu ${ }^{1}$, Hui-Juan Shi ${ }^{2}$, Hui-Qin Zhang ${ }^{2}$, Ai-Jun Zhang ${ }^{1}$, Yi-Juan Sun ${ }^{1}$ and Yun Feng ${ }^{1}$
}

The aim of this study was to investigate whether the sperm chromatin structure assay (SCSA) results after swim-up are related to fertilization rates, embryo quality and pregnancy rates following in vitro fertilization (IVF). A total of 223 couples undergoing IVF in our hospital from October 2008 to September 2009 were included in this study. Data on the IVF process and sperm chromatin structure assay results were collected. Fertilization rate, embryo quality and IVF success rates of different DNA fragmentation index (DFI) subgroups and high DNA stainability (HDS) subgroups were compared. There were no significant differences in fertilization rate, clinical pregnancy or delivery rates between the DFI and HDS subgroups. However, the group with abnormal DFI had a lower good embryo rate. So, we concluded that the SCSA variables, either DFI or HDS after swim-up preparation, were not valuable in predicting fertilization failure or pregnancy rate, but an abnormal DFI meant a lower good embryo rate following IVF.

Asian Journal of Andrology (2011) 13, 862-866; doi:10.1038/aja.2011.77; published online 15 August 2011

Keywords: embryo; fertilization; in-vitro fertilization; sperm chromatin structure assay

\section{INTRODUCTION}

The integrity of chromosomal DNA in a spermatozoon is a prerequisite for normal fertilization and transmission of paternal genetic information. ${ }^{1}$ Under normal conditions, DNA in a mature spermatozoon is condensed and compact in structure. Up to $85 \%$ of DNA binds to protamine to form DNA-protamine complexes, which are more compacted than DNA-histone complexes in somatic cells. ${ }^{2}$ By forming these condensed and insoluble complexes, normal sperm DNA becomes highly resistant to physical or chemical stimulation and has a doughnut-shaped configuration, which can prevent DNA damage during sperm transport. ${ }^{3}$ DNA damage may be caused by numerous factors, not all of which are known.

Many tests are currently available for the measurement of sperm DNA fragmentation, ${ }^{4,5}$ including terminal deoxynucleotidyl transferase-mediated deoxyuridine triphosphate fluorescein nick end labelling assay, ${ }^{6}$ in situ nick translation assay, comet assay, ${ }^{7}$ chromomycin A3 test, ${ }^{8}$ DNA breakage detection-fluorescence in situ hybridisation technique ${ }^{9}$ and sperm chromatin structure assay (SCSA). ${ }^{10,11}$ Among these methods, the most frequently used assay in clinical studies is SCSA, which measures the stability of sperm chromatin in acid media with acridine orange. The proportion of sperm containing fragmented DNA is determined by flow cytometric analysis and is expressed as the DNA fragmentation index (DFI) and high DNA stainability (HDS).

In fact, an increasing number of studies suggest that DNA fragmentation could be used as a marker of semen quality and a predictor of outcome in assisted reproductive technology (ART). ${ }^{1}$ It has been reported that about $10 \%-20 \%$ of ejaculated spermatozoa have DNA fragmentation and that apoptosis is more prevalent in oligozoospermic samples. ${ }^{12}$ Two time-to-pregnancy studies showed that SCSA test results were significantly associated with the probability of pregnancy in normal couples who had discontinued the use of contraconceptive measures. ${ }^{9,13}$ However, the associations between sperm DNA integrity and fertilization or pregnancy rates were seldom investigated in in vitro fertilization (IVF) and intracytoplasmic sperm injection (ICSI) studies. ${ }^{2,14,15}$ On the other hand, most of the published SCSA-ART studies, which found associations between SCSA parameters and ART success rate, are based on the analysis of neat and unprepared semen. Spermatozoa used for ART are, in the vast majority of cases, prepared by density gradient centrifugation (DGC) or by a swim-up to favour the isolation of motile and morphologically normal spermatozoa. Several studies have shown that both sperm separation methods are effective in isolating spermatozoa with nicked DNA and poorly condensed chromatin as evaluated by SCSA, though various levels of efficiency were reported. ${ }^{16-21}$ Among these, three SCSA-ART studies $^{15,17,19}$ were based on DGC preparation of sperm and concluded that DFI and HDS results after sperm preparation were not predictive for the outcome of IVF and ICSI.

In this study, we aimed to investigate the efficiency of swim-up to isolate spermatozoa with damaged DNA and poorly condensed chromatin and to assess the relationship between SCSA results with this preparation method and the outcomes of IVF.

${ }^{1}$ IVF Unit, Department of Obstetrics and Gynecology, Ruijin Hospital Affiliated to Shanghai Jiao Tong University, Shanghai 200025, China and ${ }^{2}$ Shanghai Institute of Planned Parenthood Research, Shanghai 200032, China 


\section{MATERIALS AND METHODS}

\section{Patients}

A total of 223 couples undergoing IVF treatment at Ruijin Hospital (Affiliated to the Medical School of Shanghai Jiao Tong University (Shanghai, China) were included in this study from October 2008 to September 2009. Informed consents were received from all participants. All experimental procedures and sample procurements were approved by the Institutional Review Board of Ruijin Hospital.

All female partners were $<40$ years of age and had day 3 folliclestimulating hormone levels $<10 \mathrm{IU} 1^{-1}$. Cases with factors adversely affecting implantation, such as hydrosalpinx, uterine synechia, adenomyosis, myoma and uterine abnormality, were excluded. Only cases with complete SCSA data of both neat semen and sperm post-preparation for IVF were included in this study.

\section{Semen preparation}

Semen samples were collected from the 223 men (on the day of oocyte retrieval for IVF) by masturbation after 2-5 days of abstinence. All samples were prepared by swim-up. Raw ejaculates were diluted 1:1 (v/v) with Sperm Medium (MediCult, Jyllinge, Denmark). Samples were then pelleted at $400 \mathrm{~g}$ for $10 \mathrm{~min}$, and the supernatants were discarded. Then, $0.5-1.0 \mathrm{ml}$ of fresh medium was added without disturbing the pellet and incubated for $45 \mathrm{~min}$ with tubes at a $45^{\circ}$ inclination. After this procedure, the upper $0.1-0.5 \mathrm{ml}$ was removed for IVF. Two semen aliquots $(100 \mu \mathrm{l})$ that were taken from each semen sample before and after sperm swim-up were diluted to $1: 5$ with TNE buffer (0.01 moll ${ }^{-1}$ Tris- $\mathrm{HCl}, 0.15 \mathrm{moll}^{-1} \mathrm{NaCl}, 1 \mathrm{~m} \mathrm{moll}^{-1}$ EDTA, $\mathrm{pH} 7.4$ ) at room temperature and then immediately frozen at $-80{ }^{\circ} \mathrm{C}$ for subsequent SCSA analysis.

\section{IVF procedures}

Ovarian stimulation, oocyte retrieval, embryo culture, embryo transfer and pregnancy outcome follow-ups were performed as previously described. ${ }^{22}$

\section{Fertilization and embryo morphology-quality assessment}

Recovered oocytes were inseminated by conventional IVF procedures. Fertilization was assessed after $18 \mathrm{~h}$ (day 1), and embryo cleavage was assessed $24 \mathrm{~h}$ thereafter (day 2). Fertilization was considered normal if two pronuclei and two polar bodies were identified. Oocytes without visible pronuclei were considered unfertilized. Embryo morphology was evaluated on day 3 by taking into account the number and symmetry of blastomeres and the percent of fragmentation. Embryos were characterized as viable by the presence of at least five blastomeres after insemination, the absence of multinucleated blastomeres and $<30 \%$ cellular fragments. A good embryo was defined as having no fewer than eight blastomeres with $\leqslant 10 \%$ cellular fragmentation. Embryo transfers were performed $72 \mathrm{~h}$ after oocyte retrieval, and only viable embryos were selected for transfer.

\section{Sperm chromatin structure assay}

The SCSA was performed as previously described. ${ }^{11}$ On the day of analysis, stored samples were thawed in a $37{ }^{\circ} \mathrm{C}$ water bath for $30 \mathrm{~s}$ and analysed immediately. A total of $1 \times 10^{6}-2 \times 10^{6}$ cells were treated for $30 \mathrm{~s}$ with a detergent solution $(\mathrm{pH} 1.2)$ containing $0.1 \%$ Triton $\mathrm{X}$ $100,0.15 \mathrm{~mol} \mathrm{l}^{-1} \mathrm{NaCl}$ and $0.08 \mathrm{~mol} \mathrm{l}^{-1} \mathrm{HCl}$ and then stained with $6 \mathrm{mg}^{-1}$ purified acridine orange (Sigma, St Louis, MO, USA) in a phosphate citrate buffer ( $\mathrm{pH}$ 6.0). Stained cells were analysed by a fluorescence activated cell sorter scan flow cytometer (Cell Lab Quanta SC; Beckman Coulter, Fullerton, CA, USA) and a minimum of 10000 events was accumulated for each measurement. After excitation with a $488-\mathrm{nm}$ light source, acridine orange bound to double-strain DNA emits green fluorescence and acridine orange bound to single-strain DNA emits red fluorescence. These results are displayed as red (fragmented DNA) versus green (DNA stainability) fluorescence intensity cytogram patterns. The extent of DNA denaturation is expressed as the DFI, which is the ratio of red to total fluorescence intensity, i.e., the level of denatured DNA over the total DNA. High DNA stainability (\% HDS) was calculated based on the percentage of sperm with high levels of green fluorescence, which are thought to represent immature spermatozoa with incomplete chromatin condensation.

\section{Statistical analysis}

Data are presented as mean \pm s.d. To determine whether higher or lower values of DFI affected pregnancy, two categories of DFI intervals ( $\leqslant 27 \%$ and $>27 \%$ ) were defined based on published results. ${ }^{23}$ HDS intervals were defined as $\leqslant 15 \%$ and $>15 \%$. Differences in reproductive outcomes (e.g., pregnancy rate, fertilization rate, embryo quality and abortion rate) between the two DFI and HDS groups were compared using Chi-square test, independent $t$-test and one-way ANOVA test. Statistical analysis was performed using SPSS 14.0 for Windows (SPSS Inc., Chicago, IL, USA). The term 'statistically significant' was used to denote a two-sided test with a $P$ value of $<0.05$.

\section{RESULTS}

Descriptive statistics of sperm parameters evaluated for neat and postswim-up are shown in Table 1. In the present study, the percentage of motile cells increased from $49.5 \% \pm 12.7 \%$ to $87.8 \% \pm 6.4 \%$, and the majority of samples showed improvement in DFI and HDS after swim-up preparation. There were 44 cases that showed DFI $>27 \%$ and 39 cases with HDS $>15 \%$ in neat semen samples. However, the corresponding figures post-swim-up were 21 and 29 cases for the DFI $>27 \%$ and HDS $>15 \%$, respectively. For 256 treatment cycles, mean DFI (mean \pm s.d.) decreased from $14.3 \% \pm 11.2 \%$ to $4.9 \% \pm 3.1 \%$ after swim-up, whereas the corresponding figures for HDS were $9.1 \% \pm 4.2 \%$ and $4.6 \% \pm 3.0 \%$, both the difference are statistical significant $(P<0.05)$ (Table 1$)$.

Descriptive analyses of data for couples receiving IVF are summarized in Tables 2 and 3. In these couples undergoing IVF, no statistically significant differences were found between the two DFI groups and the two HDS groups regarding male or female age, years of infertility and main diagnosis of infertility $(P>0.05)$ (Table 2). No statistically

Table 1 Semen analysis parameters before and after swim-up preparation

\begin{tabular}{|c|c|c|}
\hline Parameters & Neat & Swim-up \\
\hline \multicolumn{3}{|c|}{ Concentration $\left(\times 10^{6} \mathrm{ml}^{-1}\right)$} \\
\hline Mean \pm s.d. & $64.2 \pm 33.6$ & $29.3 \pm 27.4$ \\
\hline Median (range) & $66.3(24.2-210.0)$ & $27.8(21.5-40.6)$ \\
\hline \multicolumn{3}{|l|}{ Motility (\%) } \\
\hline Mean \pm s.d. & $49.5 \pm 12.7$ & $87.8 \pm 6.4$ \\
\hline Median (range) & $47.9(34.2-73.1)$ & 88.5 (79.4-93.0) \\
\hline \multicolumn{3}{|l|}{ DFI (\%) } \\
\hline 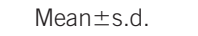 & $14.3 \pm 11.2$ & $4.9 \pm 3.1 *$ \\
\hline Median (range) & $12.3(1.1-71.6)$ & $2.6(0.2-54.3)$ \\
\hline \multicolumn{3}{|l|}{ HDS (\%) } \\
\hline Mean \pm s.d. & $9.1 \pm 4.2$ & $4.6 \pm 3.0 *$ \\
\hline Median (range) & $8.4(0.8-34.2)$ & $4.2(0.1-30.6)$ \\
\hline
\end{tabular}

Abbreviations: DFI, DNA fragmentation index; HDS, high green stain. $* P<0.05$, compared with corresponding Neat. 
Table 2 Patients' background characteristics according to DFI and HDS after swim-up preparation

\begin{tabular}{|c|c|c|c|c|}
\hline \multirow{2}{*}{$\begin{array}{l}\text { Patients' background } \\
\text { characteristics }\end{array}$} & \multicolumn{2}{|c|}{$D F I$} & \multicolumn{2}{|c|}{ HDS } \\
\hline & $\leqslant 27 \%$ & $>27 \%$ & $\leqslant 15 \%$ & $>15 \%$ \\
\hline No. of cycles & 235 & 21 & 227 & 29 \\
\hline \multicolumn{5}{|l|}{ Age, year (mean \pm s.d.) } \\
\hline Female & $31.5 \pm 3.6$ & $31.9 \pm 4.0$ & $31.4 \pm 3.7$ & $31.9 \pm 4.0$ \\
\hline Male & $35.2 \pm 4.2$ & $34.9 \pm 4.4$ & $35.0 \pm 4.3$ & $35.3 \pm 4.2$ \\
\hline Years of infertility & $4.8 \pm 2.9$ & $4.3 \pm 2.4$ & $4.7 \pm 2.7$ & $4.6 \pm 3.0$ \\
\hline \multicolumn{5}{|c|}{ Main infertility diagnosis, $n(\%)$} \\
\hline Tubal & $102(43.5)$ & $9(42.9)$ & $97(42.7)$ & $14(48.2)$ \\
\hline Endometriosis & $25(10.5)$ & $2(9.6)$ & $26(11.5)$ & $1(3.5)$ \\
\hline Ovulation failure & $6(2.6)$ & $1(4.7)$ & $5(2.2)$ & $2(6.9)$ \\
\hline Asthenospermia & $74(31.5)$ & $8(38.1)$ & $72(31.7)$ & $10(34.5)$ \\
\hline Unexplained & $28(11.9)$ & $1(4.7)$ & 27 (11.9) & $2(6.9)$ \\
\hline
\end{tabular}

Abbreviations: DFI, DNA fragmentation index; HDS, high green stain.

Table 3 Comparison of IVF outcomes according to DFI and HDS after swim-up preparation

\begin{tabular}{|c|c|c|c|c|}
\hline \multirow{2}{*}{ IVF outcomes } & \multicolumn{2}{|c|}{$D F I$} & \multicolumn{2}{|c|}{ HDS } \\
\hline & $\leqslant 27 \%$ & $>27 \%$ & $\leqslant 15 \%$ & $>15 \%$ \\
\hline $\begin{array}{l}\text { No. of oocyte } \\
\text { retrieved } \\
\text { (mean } \pm \text { s.d.) }\end{array}$ & $12.4 \pm 4.9$ & $13.1 \pm 5.8$ & $12.4 \pm 5.1$ & $12.9 \pm 5.4$ \\
\hline Fertilization rate (\%) & 65.9 & 61.4 & 64.2 & 63.8 \\
\hline Cleavage rate (\%) & 97.5 & 98.1 & 97.8 & 97.4 \\
\hline Viable embryo rate (\%) & 64.2 & 61.8 & 64.8 & 61.4 \\
\hline Good embryo rate (\%) & $27.5^{*}$ & 13.2 & 25.2 & 22.8 \\
\hline Embryo transfer ( $n$ ) & 199 & 19 & 193 & 25 \\
\hline $\begin{array}{l}\text { No. of embryo } \\
\text { transferred } \\
\text { (mean } \pm \text { s.d.) }\end{array}$ & $2.0 \pm 0.1$ & $2.1 \pm 0.2$ & $2.0 \pm 0.1$ & $2.0 \pm 0.1$ \\
\hline $\begin{array}{l}\text { Biochemical } \\
\text { pregnancies } \\
\text { rate }(\% \text { per ET) }\end{array}$ & $37.2(74 / 199)$ & $36.8(7 / 19)$ & $37.8(73 / 193)$ & $32.0(8 / 25)$ \\
\hline $\begin{array}{l}\text { Clinical pregnancies } \\
\text { rate }(\% \text { per ET) }\end{array}$ & $35.7(71 / 199)$ & $36.8(7 / 19)$ & $37.3(72 / 193)$ & $24.0(6 / 25)$ \\
\hline Implantation rate (\%) & $22.1(88 / 398)$ & $22.5(9 / 40)$ & $23.2(90 / 388)$ & $14.0(7 / 50)$ \\
\hline Abortion rate (\%) & $7.0(5 / 71)$ & $14.3(1 / 7)$ & $6.9(5 / 72)$ & $16.7(1 / 6)$ \\
\hline $\begin{array}{r}\text { Ongoing pregnancies/ } \\
\text { birth rate (\% per ET) }\end{array}$ & $33.2(66 / 199)$ & $31.6(6 / 19)$ & $34.7(67 / 193)$ & $20.0(5 / 25)$ \\
\hline
\end{tabular}

Abbreviations: DFI, DNA fragmentation index; ET, embryo transfer; HDS, high green stain; IVF, in vitro fertilization.

$* P<0.05$, compared with the DFI $>27 \%$ group

significant differences in IVF outcomes regarding number of oocytes retrieved, fertilization rate, viable embryo rate, clinical pregnancy rate and abortion rate were observed between the two DFI groups and the two HDS groups $(P>0.05)$. One difference noted between the two DFI groups was that the good embryo rate in the DFI $\leqslant 27 \%$ group was significantly higher than in the DFI $>27 \%$ group $(27.5 \%$ vs. $13.2 \%$; $P<0.05$ ) (Table 3).

In addition, the relationship between sperm DNA fragmentation and fertilization rate was also analysed. No difference in percentage of patients with low, moderate-low and normal fertilization rate intervals $(<30 \%, 30 \%-65 \%$ and $>65 \%)$ between the two DFI groups and the two HDS groups was observed $(P>0.05)$ (Table 4). However, the percentage of embryos with a fragmentation percentage of $11 \%-30 \%$ was
Table 4 Percentages of couples with different fertilization rates ( $<30 \%, 30-65 \%$ and $>65 \%$ ) in DFI and HDS groups after swim-up preparation

\begin{tabular}{lccllll}
\hline \multirow{2}{*}{ Fertilization rate } & \multicolumn{2}{c}{ DFI } & & \multicolumn{2}{c}{ HDS } \\
\cline { 2 - 3 } \cline { 6 - 7 } & $\leqslant 27 \%$ & $>27 \%$ & & $\leqslant 15 \%$ & $>15 \%$ \\
\hline No. of cycles & 235 & 21 & & 227 & 29 \\
Low $(<30 \%), n(\%)$ & $20(8.5)$ & $2(9.5)$ & & $18(7.9)$ & $4(13.8)$ \\
Moderate (30\%-65\%), & $52(22.1)$ & $3(14.3)$ & & $47(20.7)$ & $8(27.6)$ \\
$\quad n(\%)$ & & & & & \\
Normal (>65\%), n(\%) & $163(69.4)$ & $16(76.2)$ & & $162(71.4)$ & $17(58.6)$ \\
\hline
\end{tabular}

Abbreviations: DFI, DNA fragmentation index; HDS, high green stain.

Table 5 Comparison of embryo development according to DFI and HDS after swim-up preparation

\begin{tabular}{llll}
\multicolumn{2}{c}{$D F I$} & & \multicolumn{2}{c}{$H D S$} \\
& $>27 \%$ & $\leqslant 15 \%$ & $>15 \%$
\end{tabular}

No. of embryo fragmentation

at different levels (\%), $n(\%)$

Total No.

$1 \%-10 \%$

$11 \%-30 \%$

$31 \%-50 \%$

$>50 \%$

No. of embryo fragmentation

$\begin{array}{lll}1752 & 225 & 1685\end{array}$

$442(25.2) \quad 45(20.0) \quad 420(24.9) \quad 67(22.9)$

$652(37.2) \quad 73(32.4) \quad 607(36.1) \quad 118(40.4)$

$448(25.6)^{*} \quad 80(35.6) \quad 451(26.7) \quad 77(26.4)$

$90(5.5) \quad 14(6.2) \quad 92(5.5) \quad 12(4.1)$

$120(6.8) \quad 13(5.82) \quad 115(6.8) \quad 18(6.2)$

at different development

stages, $n(\%)$

8-10 cells $\quad 619(35.3) \quad 74(32.9) \quad 586(34.8) \quad 107(36.6)$

6-7 cells $\quad 608(34.7) \quad 82(36.4) \quad 588(34.9) \quad 102(34.9)$

5 cells $\quad 344(19.6) \quad 49(21.8) \quad 343(20.4) \quad 50(17.1)$

$<5$ cells $\quad 181(10.4) \quad 20(8.9) \quad 168(9.9) \quad 33(11.4)$

Abbreviations: DFI, DNA fragmentation index; HDS, high green stain.

* $P<0.05$, compared with DFI $>27 \%$ group.

significantly higher in the DFI $>27 \%$ group than in the $\leqslant 27 \%$ group (35.6\% vs. $25.6 \%, P<0.05)$ (Table 5). Nevertheless, no association between SCSA parameters and number of blastomeres was observed.

\section{DISCUSSION}

In this study, we focused on the possible predictive value of SCSA analysis for sperm after swim-up. The main conclusion that can be drawn from the current study is that assessment of sperm DNA damage after swim-up preparation can only predict the quality of embryos but not the outcome of IVF.

DNA strand breaks in human spermatozoa are indicators of deteriorated functions. Sperm DNA damage may occur due to the following mechanisms: first, protamine deficiency, a genetic disorder that is more common in infertile men, in which the protective function of DNA is diminished; ${ }^{24}$ second, oxidative stress due to leucocytosis or varicocele, which is also associated with sperm DNA damage; ${ }^{25}$ and third, increased apoptotic activity in older men and in those with abnormal semen parameters may also contribute to DNA damage. ${ }^{26}$ Systems for DNA repair are less active in the later stages of spermatogenesis, which allow sperm with DNA strand breaks to enter the ejaculate. $^{13}$

Sperm chromatin structure assays have been used to assess the extent of sperm DNA fragmentation and to predict the outcome of ART. Some studies have demonstrated the threshold for negative 
pregnancy outcomes after ART. ${ }^{15,27,28}$ However, discrepancies exist in the association between the fraction of defective sperm and fertilization rate, embryo quality and pregnancy rate and whether the technique should be used in the context of IVF or ICSI. ${ }^{29-32}$ According to a systematic review involving 2162 cycles of IVF/ICSI treatment, ${ }^{30}$ there was a lack of strong evidence of a clinical indication for the routine use of SCSA in the evaluation of infertile men, and it should be determined which subgroup of infertile couples may benefit from this test. In addition, several authors have claimed that it is necessary to conduct studies aimed at clarifying the predictive value of processed semen in ART. ${ }^{18,33,34}$

In the present study, the majority of the samples showed an improvement in DFI and HDS after swim-up preparation, which suggests that the preparation removed a significant amount of spermatozoa with DNA breaks as measured by SCSA. Several papers have demonstrated that sperm preparation may initially decrease the fraction of defective sperm in neat semen though with different net performances. ${ }^{18,35-39}$ On the other hand, Zini et al. ${ }^{18,40}$ and Tomsu et al. ${ }^{41}$ also reported either no change or a decrease in sperm quality.

To date, several published SCSA-ART studies used prepared semen for SCSA analysis, ${ }^{15,17,19}$ and all concluded that SCSA parameters with DGC or swim-up samples were not predictive for pregnancy outcomes, though there are no published data regarding the relationship between SCSA parameters and embryo quality. In the present study, which included 223 patients, the quality of embryos that were developed from high or low DFI sperm showed differences in cell fragmentation, though no relationship between SCSA parameters after swim-up and low fertilization rate and pregnancy outcomes in IVF was observed. Among a total of 225 embryos that originated from spermatozoa with DFI $>27 \%$, the percentage of embryos with blastomere fragmentation $\leqslant 10 \%$ (normally classified as good embryos) was lower than that from normal DFI sperm, though no statistically significant difference was observed. However, the percentage of embryos with fragmentation in $11 \%-30 \%$ on day 3 , which is the lowest criterion to be classified as 'viable', was significantly higher in the high DFI group than in the normal DFI group (35.6\% vs. $25.6 \%$ ). Thus, the viable embryo frequency was the same in the different DFI interval groups, but the good embryo frequency in the high DFI group decreased significantly. Therefore, our results suggest that although sperm DNA damage after swim-up did not preclude fertilization and embryo development, it did contribute significantly to the failure of good embryo development.

The embryonic genome is activated on day 3 , and the transcriptional products may supersede the regulatory control by maternal messages stored in the oocyte. Although oocytes and embryos can repair sperm DNA damage, there is a threshold beyond which sperm DNA cannot be repaired, the effects of which may influence embryo quality. Seli et al. ${ }^{26}$ reported that blastocyst stage embryo development shows a significant negative correlation with the extent of nuclear DNA fragmentation in ejaculated spermatozoa used in IVF. Larson et al. ${ }^{17}$ suggested that elevated DFI in neat semen may reflect chromatin or other abnormalities within the entire sperm population; this can interfere with the fertilizing ability of the sperm but is not completely eliminated by DGC or swim-up. According to a study by Avendaño et al., ${ }^{42}$ DNA fragments among morphologically normal sperm after swim-up preparation were more meaningful than total sperm (morphologically normal and abnormal). They found that based on a terminal deoxynucleotidyl transferase-mediated deoxyuridine triphosphate fluorescein nick end labelling (TUNEL) assay, motile spermatozoa selected by the swim-up technique containing more than $17.6 \%$ of morphologically normal sperm with fragmented DNA are associated with a higher possibility of generating poor quality embryos and are less likely to result in pregnancy.

Based on the results of current study, we conclude that neither DFI nor HDS SCSA variables after swim-up preparation were valuable in predicting fertilization failure and pregnancy rate, although our data support a clear relationship between DFI and good embryo rate on day 3 that may result in a decreased cumulative pregnancy rate. It should be noted that SCSA is a generalized test of sperm chromatin stability, but it still cannot precisely detect the type of sperm DNA breaks (single/double-strand breaks). We cannot exclude the possibility that an unknown type of damage may also exist in the sperm, although DNA denaturation does not occur during the SCSA procedure. Future research should focus on the development of the appropriate tests to specifically identify types of DNA defects and quantity threshold of damaged DNA that may affect fertility. In addition, future studies are needed to identify and isolate spermatozoa with intact DNA for ART use.

\section{CONCLUSIONS}

The SCSA variables, either DFI or HDS after swim-up preparation, were not valuable in predicting fertilization failure and pregnancy rate; however, abnormal DFI is indicative of a lower rate of good embryos following IVF.

\section{AUTHOR CONTRIBUTIONS}

ZHN participated in the design of the study, data analysis, interpretation and drafting of the manuscript. AJZ and YJS helped drafting the manuscript. HJS, HQZ and YF helped critical review and approval of article. All authors contributed extensively to the work presented in this paper.

\section{COMPETING FINANCIAL INTERESTS}

The authors declare no competing financial interests.

\section{ACKNOWLEDGMENTS}

This study was supported by grants from the Natural Science Foundation of Shanghai (No. 10JC1410800). The support of Jian-Bin Liu in collecting the patient data is gratefully acknowledged.

1 Agarwal A, Said TM. Role of sperm chromatin abnormalities and DNA damage in male infertility. Hum Reprod Update 2003; 9: 331-45.

2 Erenpreiss J, Spano M, Erenpreisa J, Bungum M, Giwercman A. Sperm chromatin structure and male fertility: biological and clinical aspects. Asian J Androl 2006; 8: 11-29.

3 Philpott A, Leno GH. Nucleoplasmin remodels sperm chromatin in Xenopus egg extracts. Cell 1992; 69: 759-67

4 de Jonge $C$. The clinical value of sperm nuclear DNA assessment. Hum Fertil2002; 5 : 51-3.

5 Dolores J. Semen analysis in 21st century medicine: the need for sperm function testing. Asian J Androl 2010; 12: 64-70.

6 Gorczyca W, Traganos F, Jesionowska H, Darzynkiewicz Z. Presence of DNA strand breaks and increased sensitivity of DNA in situ to denaturation in abnormal human sperm cells: analogy to apoptosis of somatic cells. Exp Cell Res 1993; 207: 202-5.

7 Hughes CM, Lewis SE, McKelvey-Martin VJ, Thompson W. A comparison of baseline and induced DNA damage in human spermatozoa from fertile and infertile men, using a modified comet assay. Mol Hum Reprod 1996; 2: 613-9.

8 Manicardi GC, Bianchi PG, Pantano S, Azzoni P, Bizzaro D et al. Presence of endogenous nicks in DNA of ejaculated human spermatozoa and its relationship to chromomycin A3 accessibility. Biol Reprod 1995; 52: 864-7.

9 Fernández JL, Gosálvez J. Application of FISH to detect DNA damage: DNA breakage detection-FISH (DBD-FISH). Methods Mol Biol 2002; 203: 203-16.

10 Evenson DP, Jost LK, Marshall D, Zinaman MJ, Clegg E et al. Utility of the sperm chromatin structure assay as a diagnostic and prognostic tool in the human fertility clinic. Hum Reprod 1999; 14: 1039-49. 
11 Bungum M, Bungum L, Giwercman A. Sperm chromatin structure assay (SCSA): a tool in diagnosis and treatment of infertility. Asian J Androl 2011; 13: 69-75.

12 Oosterhuis GJ, Mulder AB, Kalsbeek-Batenburg EM, Lambalk CB, Schoemaker J et al. Measuring apoptosis in human spermatozoa: a biological assay for semen quality? Fertil Steril 2000; 74: 245-50.

13 Spano M, Bonde JP, Hjollund HI, Kolstad HA, Cordelli E. Sperm chromatin damage impairs human fertility. The Danish First Pregnancy Planner Study Team. Fertil Steril 2000; 73: 43-50.

14 Lewis SE, Aitken RJ. DNA damage to spermatozoa has impacts on fertilization and pregnancy. Cell Tissue Res 2005; 322: 33-41.

15 Agarwal A, Allamaneni SS. Sperm DNA damage assessment: a test whose time has come. Fertil Steril 2005; 84: 850-3.

16 Larson KL, Brannian JD, Timm BK, Jost LK, Evenson DP. Density gradient centrifugation and glass wool filtration of semen remove spermatozoa with damaged chromatin structure. Hum Reprod 1999; 14: 2015-9.

17 Larson KL, DeJonge CJ, Barnes AM, Jost LK, Evenson DP. Sperm chromatin structure assay parameters as predictors of failed pregnancy following assisted reproductive techniques. Hum Reprod 2000; 15: 1717-22.

18 Gandini L, Lombardo F, Paoli D, Caruso F, Eleuteri P et al. Full-term pregnancies achieved with ICSI despite high levels of sperm chromatin damage. Hum Reprod 2004; 19: 1409-17.

19 Bungum M, Spano M, Humaidan P, Eleuteri P, Rescia M et al Sperm chromatin structure assay parameters measured after density gradient centrifugation are not predictive for the outcome of ART. Hum Reprod 2008; 23: 4-10.

20 Matsuura R, Takeuchi T, Yoshida A. Preparation and incubation conditions affect the DNA integrity of ejaculated human spermatozoa. Asian J Androl 2010; 12: 753-9.

21 Chiamchanya C, Kaewnoonual N, Visutakul P, Manochantr S, Chaiya J. Comparative study of the effects of three semen preparation media on semen analysis, DNA damage and protamine deficiency, and the correlation between DNA integrity and sperm parameters. Asian J Androl 2010; 12: 271-7.

22 Niu Z, Feng Y, Zhang A, Sun Y, Zhang H. Progesterone levels on oocyte retrieval day can predict the quantity of viable embryos but not pregnancy outcome of intracytoplasmic sperm injection. Gynecol Endocrinol 2008; 24: 452-8.

23 Boe-Hansen GB, Fedder J, Ersboll AK, Christensen P. The sperm chromatin structure assay as a diagnostic tool in the human fertility clinic. Hum Reprod 2006; 21 : 360-8.

24 Carrell DT, Liu L. Altered protamine 2 expression is uncommon in donors of known fertility, but common among men with poor fertilizing capacity, and may reflect other abnormalities of spermiogenesis. J Androl 2001; 22: 604-10.

25 Saleh RA, Agarwal A, Sharma RK, Said TM, Sikka SC et al. Evaluation of nuclear DNA damage in spermatozoa from infertile men with varicocele. Fertil Steril 2003; 80: 1431-6.

26 Seli E, Gardner DK, Schoolcraft WB, Moffat O, Sakkas D. Extent of nuclear DNA damage in ejaculated spermatozoa impacts on blastocyst development after in vitro fertilization. Fertil Steril 2004; 82: 378-83.

27 Sun JG, Jurisicova A, Casper RF. Detection of deoxyribonucleic acid fragmentation in human sperm: correlation with fertilization in vitro. Biol Reprod 1997; 56: 602-7.
28 Duran EH, Morshedi M, Taylor S, Oehninger S. Sperm DNA quality predicts intrauterine insemination outcome: a prospective cohort study. Hum Reprod 2002; 17: 3122-8

29 Virro MR, Larson-Cook KL, Evenson DP. Sperm chromatin structure assay (SCSA) parameters are related to fertilization, blastocyst development, and ongoing pregnancy in in vitro fertilization and intracytoplasmic sperm injection cycles. Fertil Steril 2004; 81: 1289-95.

30 Bungum M, Humaidan P, Spano M, Jepson K, Bungum L et al. The predictive value of sperm chromatin structure assay (SCSA) parameters for the outcome of intrauterine insemination, IVF and ICSI. Hum Reprod 2004; 19: 1401-8.

31 Payne JF, Raburn DJ, Couchman GM, Price TM, Jamison MG et al. Redefining the relationship between sperm deoxyribonucleic acid fragmentation as measured by the sperm chromatin structure assay and outcomes of assisted reproductive techniques. Fertil Steril 2005; 84: 356-64.

32 Collins JA, Barnhart KT, Schlegel PN. Do sperm DNA integrity tests predict pregnancy with in vitro fertilization? Fertil Steril 2008; 89: 823-31.

33 Tarozzi N, Bizzaro D, Flamigni C, Borini A. Clinical relevance of sperm DNA damage in assisted reproduction. Reprod Biomed Online 2007; 14: 746-57.

34 Tomlinson MJ, Moffat O, Manicardi GC, Bizarro D, Afnan M et al. Interrelationships between seminal parameters and sperm nuclear DNA damage before and after density gradient centrifugation: implications for assisted conception. Hum Reprod 2001; 16: 2160-5.

35 Donnelly ET, O'Connell M, McClure N, Lewis SE. Differences in nuclear DNA fragmentation and mitochondrial integrity of semen and prepared human spermatozoa. Hum Reprod 2000; 15: 1552-61.

36 Donnelly ET, McClure N, Lewis SE. Cryopreservation of human semen and prepared sperm: effects on motility parameters and DNA integrity. Fertil Steril 2001; 76: 892900 .

37 Sakkas D, Manicardi GC, Tomlinson M, Mandrioli M, Bianchi PG et al. The use of two density gradient centrifugation techniques and the swim-up method to separate spermatozoa with chromatin and nuclear anomalies. Hum Reprod 2000; 15: 1112-6.

38 Lachaud C, Tesarik J, Canadas ML, Mendoza C. Apoptosis and necrosis in human ejaculated spermatozoa. Hum Reprod 2004; 19: 607-10.

39 Piomboni P, Bruni E, Capitani S, Gambera L, Moretti E et al. Ultrastructural and DNA fragmentation analyses in swim-up selected human sperm. Arch Androl 2006; 52: 51-9.

40 Zini A, Mak V, Phang D, Jarvi K. Potential adverse effect of semen processing on human sperm deoxyribonucleic acid integrity. Fertil Steril 1999; 72: 496-9.

41 Tomsu M, Sharma V, Miller D. Embryo quality and IVF treatment outcomes may correlate with different sperm comet assay parameters. Hum Reprod 2002; 17: 1856-62.

42 Avendaño C, Franchi A, Duran H, Oehninger S. DNA fragmentation of normal spermatozoa negatively impacts embryo quality and intracytoplasmic sperm injection outcome. Fertil Steril 2010; 94: 549-57. 